\title{
INCREASING CYCLONE EFFICIENCY BY USING A SEPARATOR PLATE
}

\author{
Janis Galins, Aigars Laizans, Ainars Galins \\ Latvia University of Life Sciences and Technologies, Latvia \\ janis.galins@llu.lv
}

\begin{abstract}
The aim of the work is to increase the efficiency of cyclone technology by using a separator plate. Cyclone technology is used not only in the processing of various agricultural products, but also in air purification from dust. Air flow trajectories and the movement of dust particles inside the cyclone unit were simulated and analyzed using Computational Fluid Dynamics (CFD) and particle study analyses. The separator plate was designed in certain sizes and placed inside the cyclone, thus increasing the efficiency of the cyclone. The angle of position of the separator plate significantly affected the obtained results. The experimental equipment was assembled together to test the simulation results. Wood ash was used to determine the efficiency of the cyclone. Studies have shown that the effect of the separator plate on increasing the efficiency of the experimental equipment is less than that shown in the simulations. Most of the experiments used ash particles that were greater than $20 \mu \mathrm{m}$, thus cyclone efficiency was $98.9 \pm 0.05 \%$. This confirms the compliance of CFD simulations with the physical model. More detailed research should be carried out in order to use the separator plate effectively for the filtration of very small dust particles.
\end{abstract}

Key words: cyclone separator, separation efficiency, flow Simulation particle study, computational fluid dynamics.

\section{Introduction}

In the production areas, air may contain large amounts of small solid particles of dust. By using such air for cooling electrical equipment, the cooling channels and radiators overlap with the dust layer and greatly reduce the cooling capacity. There are cases when dust, fluffs and various matter of different shapes block the ventilation ducts. High-quality air preparation is required to increase the cooling stability of electrical equipment. Various filters are widely used, but filters have a limited filtering time, they have to be cleaned regularly, and air filters greatly increase the air resistance (Medvedkov \& Selimgareev, 2017; Zhang et al., 2017; Feng et al., 2018). Studies have been made on how to maximize the effectiveness of dust filtering. One of the more effective options for separating particles of different sizes of dust and mechanical impurities is cyclone technology (Ganegama Bogodage \& Leung, 2015). The study used SolidWorks Flow Simulation tools to develop an effective cyclone constructive solution. As a result, an air purification cyclone solution was obtained, which could be applied not only to the electrical cooling system, but also used for other applications, including the processing of agricultural products. Similar technologies can be used to produce various dried products, such as milk and egg powder (Yildirim \& Genc, 2017). It is possible that the cyclone's efficiency can be increased by stopping the turbulence of the mid-part of the cyclone because the sucked particles from the bottom of the cyclone are continuously raised upwards (see Fig. 1.).

The lack of cyclone air purification equipment is a reduction in efficiency when sucking small dust particles. Airflow trajectories show that small particles of dust are affected by turbulence, so they hit the bottom of the cyclone and move up the middle of the cyclone (Balestrin et al., 2017; Ganegama Bogodage \& Leung, 2015; Wasilewski, 2017).

Dust is small, solid particles of mineral or organic material. Dust particle sizes can range from 0.5 to $100 \mu \mathrm{m}$; depending on the size, they can stay in the air longer or shorter. The dust is divided into visible dust (with particle sizes above $10 \mu \mathrm{m}$ ), microscopic $(0.25$ to $10 \mu \mathrm{m})$ and ultra-microscopic (below $0.25 \mu \mathrm{m}$ ) (Engineering ToolBox, 2005; Particle Size and Distribution, n.d.). The efficiency of the cyclone is influenced by various parameters: cyclone shape and size; particle size and density; air flow velocity; surface friction; properties of gas; temperature. Vortex length and flow regimes play an important role on cyclone performance especially in small cyclones (Particle Size and Distribution, n.d.; Mariani F., Risi F., Grimaldi C.N., 2017; Singh et al., 2017; Zhao $\& \mathrm{Su}, 2018)$. The aim of the work is to increase the efficiency of cyclone technology by using a separator plate.

\section{Materials and Methods}

The research was conducted in the Institute of Energetics of Faculty of Engineering, Latvia University of Life Sciences and Technologies on March 10, 2018. A vacuum cleaner was used to run the experimental equipment. In order to determine the efficiency of the experimental equipment, wood ash was used instead of dust. The coal from the ash was separated using a metal mesh with circular holes $4 \mathrm{~mm}$ in the diameter. KERN PNJ 3000-2M Version 1.2 04/2016 scales were used for weighing. The bucket mass and the vacuum cleaner filter were weighed first, and $700 \mathrm{~g}$ ash was then placed in the bucket. The ash was sucked through the entrance of the experimental equipment in about 60 seconds. After sucking, the bucket mass was compared with the previously weighed bucket 


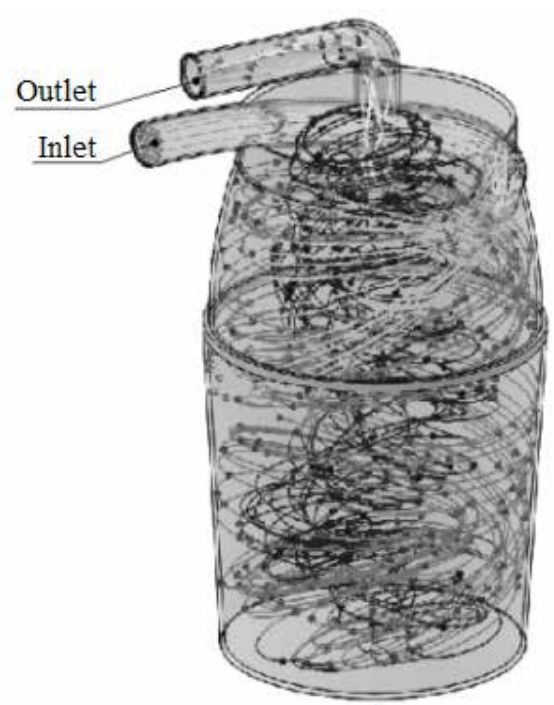

a)

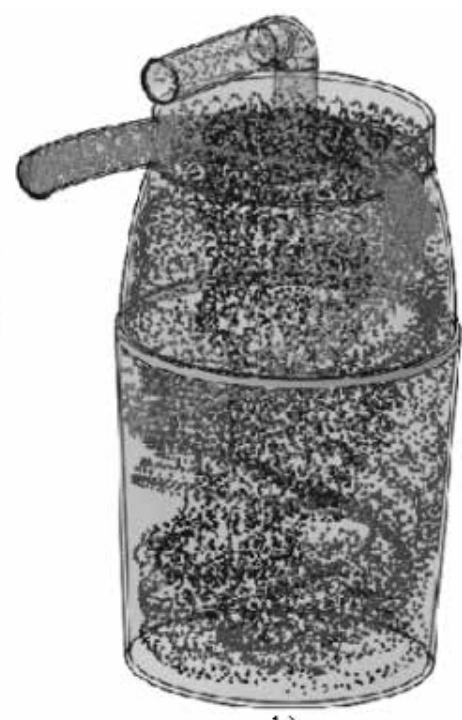

b)

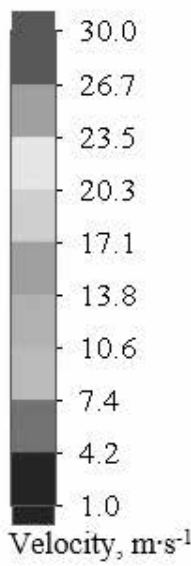

Figure 1. Simulation of cyclone type air purification plant (created by the author): a) - air flow velocity; b) dust particle study.

mass value to make sure that the whole $700 \mathrm{~g}$ ash mass was absorbed. The mass of the vacuum cleaner filter was then weighed again and the ash mass was calculated as the difference. Equation 1 was used to calculate the cyclone efficiency (\%) of the experimental equipment.

Cycloneefficiency $=\frac{\text { Totalashmass }- \text { Ashmass } \in \text { filter }}{\text { Totalashmass }} \cdot 100$

Five experiments were performed without a separator plate and five with a separator plate. After each experiment, the vacuum cleaner filter and cyclone were thoroughly cleaned of ashes.

To measure the air temperature in the room, the SA880SSX electronic thermometer with a stainless steel probe was used. The room temperature was $18.5^{\circ} \mathrm{C}$.

The digital anemometer DK801695 with velocity measuring range 0 to $30 \mathrm{~m} \mathrm{~s}^{-1}$, resolution $0.1 \mathrm{~m} \mathrm{~s}^{-1}$ and precision $\pm 5 \%$ was used to measure the air flow velocity. An extension with a diameter of $70 \mathrm{~mm}$ was added to the end of the cyclone input to allow the measured airflow velocity to fall within the measuring range. Without the separator plate, the air flow velocity was 5.4 to $5.8 \mathrm{~m} \mathrm{~s}^{-1}$, the average value was $5.6 \mathrm{~m} \mathrm{~s}^{-1}$. The separator plate slightly increased the airflow resistance and the measured air flow velocity decreased from 4.9 to $5.5 \mathrm{~m} \mathrm{~s}^{-1}$. The average value was $5.3 \mathrm{~m} \mathrm{~s}^{-1}$. The calculated air volume flow rate was $\sim 0.02 \mathrm{~m}^{3} \mathrm{~s}^{-1}$. Data from the experimental equipment was used for flow simulations and particle study (see Table 1).

Equation 2 was used to calculate the mass flow rate (see Table 1).

Total ash mass $=700 \mathrm{~g} ;$ Total experiment time $=60 \mathrm{~s}$

$$
\text { Mass flow rate }=\frac{\text { Total ash mass }}{\text { Total experiment time }}
$$

Particle size of wood ash used in the experiments was about $0.2-3 \mu \mathrm{m}$. Particle study simulations were made with particles of different sizes. The smallest particle was $0.03 \mu \mathrm{m}$ but the largest particle $100 \mu \mathrm{m}$.

\section{Results and Discussion}

Simulations were made on various sizes and locations of the separator plate (see Fig. 2).

\section{Flow simulation and particle study parameters}

\begin{tabular}{|c|c|}
\hline Parameter & Value \\
\hline Inlet pressure, $\mathrm{Pa}$ & 101325 \\
\hline Outlet volume flow rate, $\mathrm{m}^{3} \mathrm{~s}^{-1}$ & 0.02 \\
\hline Temperature, ${ }^{\circ} \mathrm{C}$ & 20 \\
\hline Mass flow rate (wood ash particles), $\mathrm{kg} \mathrm{s}^{-1}$ & 0.01167 \\
\hline
\end{tabular}




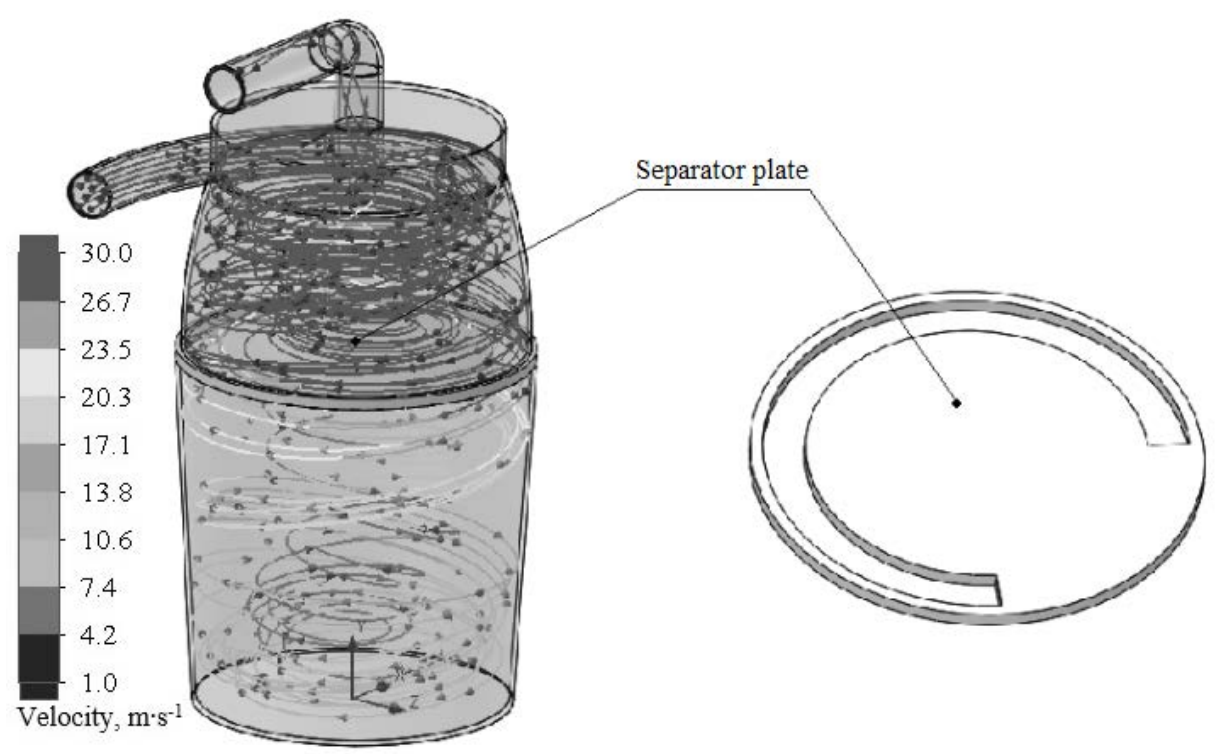

Figure 2. Simulation of cyclone type air purification plant with separator plate.

The simulation results were significantly affected by the particle size and the angle of the separator plate positioning around the $y$-axis. The larger the particle size, the faster it passes to the bottom of the cyclone. Smaller particles are harder to move under the separator plate. If the particle falls below the separator plate, it no longer moves up through the middle of cyclone. In order to use the separator plate more efficiently, its location must be placed according to the particles of the same size dust. The separator plate is difficult to use for separating particles of different sizes because the trajectory of the particle depends on the size and density.

Experimental results showed that the cyclone efficiency was $98.9 \pm 0.05 \%$. with and without the separator plate. Dry wooden ash was used for dust particles. The values of the calculated efficiency may differ more if the equipment is operated for an extended period of time with uneven mass flow rate. Cyclone without separator plate should raise the particles up from the bottom.

Using the particle study simulation tool, the cyclone without the separator plate has a curve that describes the efficiency of the cyclone, depending on the size of the particle (see Fig. 3).

The simulation results show that the cyclone with $100 \%$ efficiency filters dust particles larger than $20 \mu \mathrm{m}$. By filtering smaller particles, the cyclone efficiency gradually decreases to around $80 \%$. According to previous studies, particles larger than $120 \mu \mathrm{m}$ were filtered with nearly $100 \%$ efficiency (Barone et al., 2017), particles smaller than $5 \mu \mathrm{m}$ were filtered only with $20 \%$ efficiency (Balestrin et al., 2017). Previous studies confirm the assumption that most of the experiments used ash particles that were greater than $20 \mu \mathrm{m}$, thus cyclone efficiency was

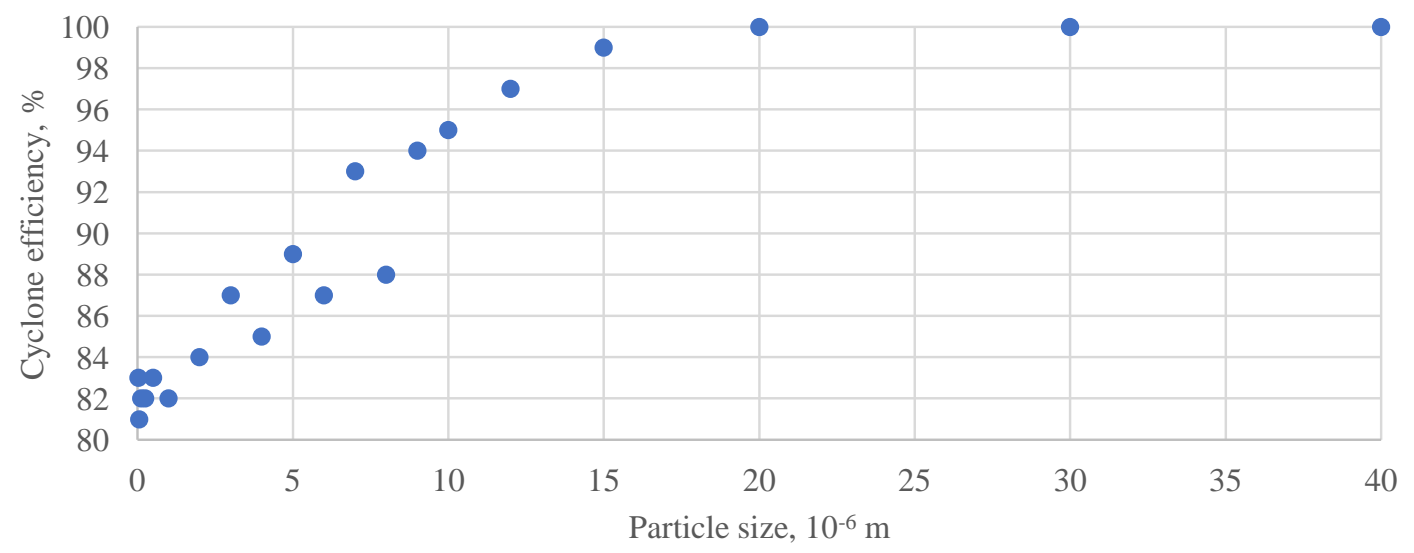

Figure 3. The cyclone efficiency depends on the size of the dust particles. 
$98.9 \pm 0.05 \%$. Compared with other studies, cyclone efficiency was greatly affected by the use of different designs and shapes of the cyclones. To obtain more accurate results, ash particles should be divided into fractions by size.

\section{Conclusions}

1. The simulation results show that the cyclone with $100 \%$ efficiency filters dust particles larger than $20 \mu \mathrm{m}$. By filtering smaller particles, the cyclone efficiency gradually decreases to around $80 \%$.

2. Most of the experiments used ash particles that were greater than $20 \mu \mathrm{m}$, thus cyclone efficiency was $98.9 \pm 0.05 \%$. This confirms the compliance of CFD simulations with the physical model.

3. More detailed research should be carried out in order to effectively use the separator plate for the filtration of very small dust particles in longer time experiments.

\section{References}

1. Balestrin, E., Decker, R.K., Noriler, D., Bastos, J.C.S.C., \& Meier, H.F. (2017). An alternative for the collection of small particles in cyclones: Experimental analysis and CFD modeling. Separation and Purification Technology, 184, 54-65. DOI: 10.1016/j.seppur.2017.04.023.

2. Barone, D., Loth, E., \& Snyder, P. (2017). Influence of particle size on inertial particle separator efficiency. Powder Technology, 318, 177-185. DOI: 10.1016/j.powtec.2017.04.044.

3. Engineering ToolBox, Particle Sizes. (2005). Retrieved February 27, 2018, from: https://www. engineeringtoolbox.com/particle-sizes-d_934.html.

4. Feng, Z., Pan, W., Zhang, H., Cheng, X., Long, Z., \& Mo, J. (2018). Evaluation of the performance of an electrostatic enhanced air filter (EEAF) by a numerical method. Powder Technology, 327, 201-214. DOI: 10.1016/j.powtec.2017.12.054.

5. Ganegama Bogodage, S., \& Leung, A.Y.T. (2015). CFD simulation of cyclone separators to reduce air pollution. Powder Technology, 286, 488-506. DOI: 10.1016/j.powtec.2015.08.023.

6. How to Understand Particle Size and Distribution for Cleaner Air. (n.d.). Retrieved February 27, 2018, from: https://www.oransi.com/particle-size-s/189.htm.

7. Mariani, F., Risi, F., \& Grimaldi, C.N. (2017). Separation efficiency and heat exchange optimization in a cyclone. Separation and Purification Technology, 179, 393-402. DOI: 10.1016/j.seppur.2017.02.024.

8. Medvedkov, I., \& Selimgareev, V. (2017). Russian air filter manufacturer eyes global markets. Filtration and Separation, 54(2), 22-25. DOI: 10.1016/S0015-1882(17)30081-2.

9. Singh, G., Saini, D., Chandra, L., \& Shekhar, R. (2017). Design of a cyclone separator for cleaning of dust from volumetric air receiver. Lecture Notes in Mechanical Engineering, Part F8, 83-93. DOI: 10.1007/97881-322-2743-4_9.

10. Wasilewski, M. (2017). Analysis of the effect of counter-cone location on cyclone separator efficiency. Separation and Purification Technology, 179, 236-247. DOI: 10.1016/j.seppur.2017.02.012.

11. Yildirim, N., \& Genc, S. (2017). Energy and exergy analysis of a milk powder production system. Energy Conversion and Management, 149, 698-705. DOI: 10.1016/j.enconman.2017.01.064.

12. Zhang, Y., Wei, Z., \& Zhang, M. (2017). Free cooling technologies for data centers: Energy saving mechanism and applications. Energy Procedia, 143, 410-415. DOI: 10.1016/j.egypro.2017.12.703.

13. Zhao, B., \& Su, Y. (2018). Particle size cut performance of aerodynamic cyclone separators: Generalized modeling and characterization by correlating global cyclone dimensions. Journal of Aerosol Science, (February), 1-11. DOI: 10.1016/j.jaerosci.2018.02.009. 